\title{
Developmental parameters and physical fitness in preschool children with Minor Neurological Dysfunction
}

\author{
Halil Alkan ${ }^{1,2}$, Akmer Mutlu $^{2 \oplus}$, Göknur Haliloğlu ${ }^{3 \odot}$ \\ ${ }^{1}$ Department of Physiotherapy and Rehabilitation, Muş Alparslan University, Faculty of Health Sciences, Muş; ${ }^{2}$ Hacettepe University \\ Faculty of Physical Therapy and Rehabilitation, Ankara; ${ }^{3}$ Department of Pediatric Neurology, Hacettepe University Faculty of \\ Medicine, Ankara, Turkey.
}

\begin{abstract}
Background. The preschool years constitute a critical period during which significant changes are experienced in the acquisition of locomotor skills due to maturation of the nervous system. Our aim was to investigate the developmental parameters and physical fitness in preschool children with Minor Neurological Dysfunction (MND).
\end{abstract}

Methods. The study was carried out in 212 preschool children without any known health problems. Sociodemographic characteristics of children were recorded. Denver Developmental Screening Test (DDST) II, Touwen Neurological Examination, and Preschool Physical Fitness (PREFIT) test battery were used to assess developmental parameters, neurological status, and physical fitness, respectively.

Results. There was a statistical difference in the physical fitness and developmental parameters in preschool children with MND compared with healthy peers $(\mathrm{p}<0.05)$. There was also a relationship between physical fitness and developmental parameters $(\mathrm{p}<0.05)$.

Conclusions. Early identification of problems in developmental parameters and physical fitness in preschool children with MND might help to implement early supportive physiotherapy and rehabilitation.

Key words: minor neurological dysfunction, physical fitness, preschool.

The preschool years are a critical period in which significant changes are experienced in the acquisition of locomotor skills due to maturation of the nervous system in children. ${ }^{1}$ In this period, children gain significant progress in terms of developmental parameters in gross-motor, fine-motor, language and socialemotional domains. ${ }^{2}$ This process, which is also affected by the environment, may show a nonoptimal pattern, although it appears normal. The exact mechanism of 'misadaptation of behavior' due to the failure of the brain to develop within normal limits is not known, and this 'non-optimal developmental process' in the brain is attributed to the altered function of

\section{Halil Alkan}

fzthalilalkan@hotmail.com

Received 14th June 2020, revised 29th July 2020,

1st September 2020, accepted 12th September 2020. neurotransmitters. ${ }^{3}$ As a result of this condition, the neurodevelopmental level of the child is reflected on problems of coordination which are uncertain movements in daily life activity, such as, impaired posture and muscle tone, insufficient gross and fine motor movements. In other words, this condition, which is defined as Minor Neurological Dysfunction (MND), may arise even as a complex MND with the increased load of involved developmental domains which further presents in the form of cerebral palsy spectrum disorder. ${ }^{4}$ Although there is no appareant symptom in the first years of life, there is the possibility to determine definitive neurological problems at preschool or school age. ${ }^{5}$ In this respect, it is important to assess the neurological status of preschool children at the earliest possible time, to detect possible dysfunction and to direct them to the right discipline in terms of both prognosis and rehabilitation. ${ }^{6}$ 
Physical activity in childhood is not only important for bone, muscle, cardiovascular and brain development, but also for healthy growth and obesity prevention., ${ }^{7,8}$ Physical fitness level is a strong indicator of health at early ages and physical activity is the main determinant of physical fitness. ${ }^{9}$ While health-related physical fitness includes muscular strength and endurance, cardiovascular endurance, flexibility and body composition; skill-related physical fitness includes coordination, speed, agility, power, balance, and reaction time. ${ }^{10}$ Depending on any reason, impairment of any physical fitness parameter affects physical fitness. $^{8}$

To the best of our knowledge, there are no studies investigating the developmental parameters and physical fitness in preschool children with MND. Therefore, our aim was to investigate developmental parameters and physical fitness in preschool children, and compare the developmental profile of children with MND and healthy peers.

\section{Material and Methods}

\section{Design and Participants}

The study was carried out in 212 preschool children (107 girls and 105 boys, aged 4-6 years) without any known health problems in schools of Muş Province, Ministry of National Education between February and June 2018. Ethical permission was obtained on 29/11/2017 from Muş Alparslan University Publication Ethics Board, with the decision number E13931, and decision number 2 . At the same time, with the decision dated 29/12/2017 and numbered 8822, official permission was obtained from Muş Provincial Directorate of National Education. The study was conducted in schools determined by simple random sampling method according to the guidelines given in the Declaration of Helsinki. Informed consent, witnessed and formally recorded, was obtained from all children and parents.
Inclusion criteria for the study were children aged 4-6 years currently attending kindergarten, without any known health problems, who could follow the directions of the physiotherapist. For statistical power analysis, Hacettepe University Faculty of Medicine Biostatistics Department was consulted. Using PASS 11.0 (Power Analysis and Sample Size) software, the number of children was determined with $90 \%$ power and $5 \%$ error rate. Of 250 children, 212 children who were able to complete the assessments were included in the statistical analysis.

\section{Measurements}

Demographic characteristics of the children in the study were recorded. Each child was evaluated respectively within a period of approximately 90 minutes. All measurements were performed in one season for each child and carried out by the Expert Physiotherapist, who has five years of experience in pediatric rehabilitation and has Denver Developmental Screening Test (DDST) II certificate. All measurements were carried out in the morning, at the playground or garden of the schools. The instructions in all measurement tests used were reviewed one by one and were implemented by ensuring standardization in all settings.

\section{Touwen Neurological Examination}

The Touwen examination is a method which comprehensively evaluates neural functions developed by Touwen and Prechtl in 1970, in eight areas including posture and muscle tonus, reflexes, involuntary movements, coordination and balance, fine-motor movements, associated movements, sensory functions and cranial nerve function. ${ }^{11}$ In these eight areas, children with no dysfunction in any area are defined as "normal"; children with dysfunction in one or two areas are defined as "Simple MND"; children with dysfunction in three or more areas are defined as "Complex MND". ${ }^{4}$ It is a standardized, detailed and age-specific assessment method that measures the quality of motor behavior in a strong and precise way, and includes 
97 items. Different positions such as sitting, standing, walking and lying are used during assessments. ${ }^{11}$ Before using this measurement method, a pilot study was carried out on 5 children by reading the Touwen Neurological Examination manual book and watching the sample case videos one by one. All the items of the Touwen neurological examination were performed in accordance with the specified guidelines.

\section{Denver Developmental Screening Test II}

Denver Developmental Screening Test (DDST) II, standardized in many countries around the world, is a screening test designed to detect developmental problems in personal-social, language, fine-motor and gross-motor areas in children aged 0-6 years. ${ }^{12}$ This test, which is valuable in terms of defining developmental problems, verifying suspicious cases with an objective criterion and following children at risk and directing them to the relevant professionals, consists of a total of 134 items that can be assisted by asking the parents and/ or caregivers as well as performance tests. ${ }^{6}$ The norm values of this test have been conducted in Turkish children. ${ }^{13,14}$

Children performing the age-appropriate items or taking only one warning item for performance are determined as "normal" in terms of development. Children who are not able to perform one item, have two or more warning items are determined as "suspicious" in terms of development. Children who can not perform two or more items as are determined as "abnormal" in terms of development., ${ }^{6,12}$ DDST II was performed according to defined, standard equipments.

\section{Physical Fitness}

To assess physical fitness, PREschool Physical FITness (PREFIT) Test Battery developed in Europe for 4-6 age range was used. This battery used in preschool children is an easy and reliable method including weight, height and waist circumference to assess anthropometry, $20 \mathrm{~m}$ shuttle run test (SRT) to assess cardiorespiratory fitness, handgrip strength and standing long jump (SLJ) tests to assess muscular strength, 4 $\times 10 \mathrm{~m}$ SRT to assess speed-agility, and one-leg stance test to assess balance. ${ }^{15,16}$

\section{Body Composition}

Height and weight were measured to the nearest $0.1 \mathrm{~cm}$ and $0.1 \mathrm{~kg}$, with wall stadiometer and an electronic scale, respectively. During the measurement, children were asked to be barefoot and minimally dressed. Body Mass Index (BMI) is calculated as body weight $(\mathrm{kg}) /$ height $(\mathrm{m})$. All measurements are repeated twice and averaged for statistical analyses. ${ }^{15,16}$

\section{Six-Minute Walk Test}

Six-Minute Walk Test (MWT) was used to assess cardiorespiratory fitness in preschool children. Six-MWT is similar to the shuttle run test assessing cardiorespiratory fitness in preschool children. It has the advantage of being more common, and it can be conducted with a single researcher, without using a video signal and tape. ${ }^{17}$

Six-MWT is a very appropriate method used in a cheap, equipment-free, practical way assessing functional exercise capacity at a submaximal level with one's own walking speed. Validity studies of Six-MWT have been conducted in healthy children and adolescents, and its standard value has been specified. According to this test, children were asked to walk as fast as possible on a flat, hard surface for 6 minutes and were encouraged verbally for test. The test distance in the pediatric population is recommended as $15-20 \mathrm{~m}$, and is determined as $20 \mathrm{~m} .{ }^{18}$ The distance measured was marked with band and the cones were placed at both ends. The total distance walked by children was recorded $(\mathrm{m}) .{ }^{17}$

\section{Handgrip Strength Test}

Hand dynamometer (TKK 5001, gripA, Takei, Tokyo; range 0-100 kg; accuracy $0.5 \mathrm{~kg}$ ) was 
used to assess the muscular strength of the upper body and upper extremity with a grip span of $4(\mathrm{~cm})$. Hand grip strength test assesses isometric muscle strength of the upper body and upper extremity. During the measurement, the children standing in a bipedal position were asked to squeeze the dynamometer continuously for at least 2 or 3 seconds without bending the elbow and contacting the body. The best value of two trials for each hand was chosen, and the average of both hands was registered $(\mathrm{kg}) \cdot{ }^{15,16}$

\section{SLJ Test}

The SLJ test was used to assess the muscular strength of the lower body and lower extremities. This test consists of jumping as far as possible behind the starting line with feet together (separate from each other approximately at the shoulder's width on a hard, non-slippery surface,) and remaining upright. Children performed three jumps and the best of these attempts was recorded $(\mathrm{cm}) \cdot{ }^{15,16}$ The starting line was marked, and the jump distance was glued to the band and scaled $(\mathrm{cm}) \cdot{ }^{15}$

\section{SRT}

The SRT was used to assess speed and agility. The test consists of running on a non-slippery surface between the two parallel lines $(10 \mathrm{~m}$ apart) drawn on the floor, covering a distance of $40 \mathrm{~m}$ and running back and forth as fast as they can. In each round, the children had to cross the finish line with both feet and touch the hand of the researcher. Children tried the test for a second time after a short rest. The best result (minimum score) of two attempts was recorded (sec). ${ }^{15,16}$ While the tester was on one side of the parallel lines during the test, one of the parents was placed to the other side of the parallel lines. ${ }^{15}$

\section{One-leg Stance Test}

One-leg stance test was used to assess the balance. According to this test, which assesses the static balance, the children maintained their balance in this position as much as they could stand on one leg while the other leg was bended from the knee. The chronometer was activated immediately after the children had lifted the free leg from the floor. Children were allowed to use their arms if it was necessary to maintain the balance position as long as possible. The test ended when the children couldn't maintain the required position, i.e. holded something, moved the supporting foot, heel or toe of the original position. The test was performed once with each leg and the mean of two attempts was registered (sec)..$^{15,16}$

\section{Statistical analysis}

Statistical analyses were performed using IBM Statistical Package for the Social Science software version 23. Visual (histograms and probability plots) and analytical methods (Kolmogorov-Smirnov / Shapiro Wilk's test) were used to determine whether or not the numerical variables were normally distributed. While investigating the associations between non-normally distributed and/or ordinal variables, the correlation coefficients and statistical significance were calculated using the Spearman test. The descriptive analyses were presented using means and standard deviations for the numerical variables which show normal distribution in the comparisons, medians and interquartile range (IQR) for the numerical variables showing non-normal distribution, number and percentage values for categorical variables. The Independent Sample $t$ test was used for the comparison of two groups with normal distribution, while the Mann-Whitney $\mathrm{U}$ test was used to compare two groups with at least one non-normal distribution. When comparing categorical independent two groups, Chi-square or Fisher's exact (when chisquare test assumptions do not hold due to the low expected cell counts) test was used. The total type-1 error level was accepted as $5 \%$ and the p-value as smaller than 0.05 for statistical significance. 


\section{Results}

The study population included 212 preschool children without any known health problems, 107 girls and 105 boys, between the ages of 4-6 years. Out of 212 children, 19 (8.9\%; 3 girls and 16 boys) who had MND were compared with the rest of the study population (Table I).

Physical fitness and developmental parameters of children who were detected to have MND according to the Touwen examination and their healthy peers were compared (Table II).
There was a significant difference in terms of physical fitness (one-leg stance) and DDST II sub-parameters (personal-social, fine motor, gross motor) ( $p<0.05)$. There was no significant difference for the other physical fitness parameters and language parameter $(p>0.05)$. Children with MND performed lower scores in physical fitness (one-leg stance) and DDST II sub-parameters (personal-social, fine motor, gross motor) compared to their healthy peers. Although not statistically significant, children with MND performed lower scores clinically

Table I. Descriptive characteristics of the study population.

\begin{tabular}{|c|c|c|c|c|}
\hline & & & $\begin{array}{c}\text { Mean } \pm \text { SD } \\
(n=212)\end{array}$ & Min-Max \\
\hline \multicolumn{3}{|c|}{ Age (months) } & $62 \pm 7$ & $44-75$ \\
\hline \multicolumn{3}{|c|}{ Weight (kg) } & $19.3 \pm 3$ & $13.2-32.5$ \\
\hline \multicolumn{3}{|c|}{ Height (cm) } & $109 \pm 6$ & $92-123$ \\
\hline \multicolumn{3}{|c|}{ BMI $\left(\mathrm{kg} / \mathrm{m}^{2}\right)$} & $16.2 \pm 1.7$ & $12.7-22.5$ \\
\hline & \multirow{6}{*}{ 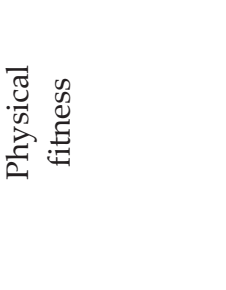 } & Handgrip (kg) & $7 \pm 1.5$ & $5-14.2$ \\
\hline & & One-leg stance (s) & $18.6 \pm 14.3$ & $3.5-94$ \\
\hline & & SLJ (cm) & $82 \pm 17$ & $37-120$ \\
\hline & & 4x10 m SRT (s) & $17.55 \pm 2$ & $14-25$ \\
\hline & & Six-MWT (m) & $396 \pm 52$ & $290-560$ \\
\hline & & & \multicolumn{2}{|c|}{$\mathrm{n}(\%)$} \\
\hline \multirow{2}{*}{\multicolumn{2}{|c|}{ Gender }} & Girls & \multicolumn{2}{|c|}{$107(50.5)$} \\
\hline & & Boys & \multicolumn{2}{|c|}{105 (49.5) } \\
\hline \multicolumn{2}{|l|}{ DDST II } & Normal & \multicolumn{2}{|c|}{$129(60.8)$} \\
\hline \multirow{10}{*}{ 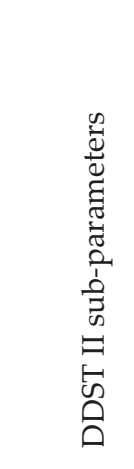 } & & Suspicious & \multicolumn{2}{|c|}{$73(34.4)$} \\
\hline & & Abnormal & \multicolumn{2}{|c|}{$10(4.7)$} \\
\hline & \multirow{2}{*}{ Personal-social } & Abnormal & \multicolumn{2}{|c|}{$21(9.9)$} \\
\hline & & Normal & \multicolumn{2}{|c|}{$191(90.1)$} \\
\hline & \multirow{2}{*}{ Fine-motor } & Abnormal & \multicolumn{2}{|c|}{$25(11.8)$} \\
\hline & & Normal & \multicolumn{2}{|c|}{$187(88.2)$} \\
\hline & \multirow{2}{*}{ Language } & Abnormal & \multicolumn{2}{|c|}{55 (25.9) } \\
\hline & & Normal & \multicolumn{2}{|c|}{$157(74.1)$} \\
\hline & \multirow{2}{*}{ Gross-motor } & Abnormal & \multicolumn{2}{|c|}{$68(32.1)$} \\
\hline & & Normal & \multicolumn{2}{|c|}{$144(67.9)$} \\
\hline \multirow{3}{*}{\multicolumn{2}{|c|}{ MND }} & Normal & \multicolumn{2}{|c|}{$193(91.0)$} \\
\hline & & Simple MND & \multicolumn{2}{|c|}{$18(8.5)$} \\
\hline & & Complex MND & \multicolumn{2}{|c|}{$1(0.5)$} \\
\hline \multirow{2}{*}{\multicolumn{2}{|c|}{ Neurological status }} & MND & \multirow{2}{*}{\multicolumn{2}{|c|}{$\begin{array}{c}19(8.9) \\
193(91.1)\end{array}$}} \\
\hline & & Normal & & \\
\hline
\end{tabular}

BMI: body mass index, DDST: denver developmental screening test, MND: minor neurological dysfunction, MWT: minute walk test, SD: standard deviation, SLJ: standing long jump, SRT: shuttle run test. 
Table II. Comparison of physical fitness and developmental parameters according to neurological status.

\begin{tabular}{|c|c|c|c|c|c|}
\hline & & & Neurc & status & \\
\hline & & & Normal & MND & \\
\hline & & & $n=193$ & $\mathrm{n}=19$ & $\mathrm{p}$ \\
\hline & & & Mean \pm SD & Mean \pm SD & \\
\hline & SLJ (cm) & & $82 \pm 16$ & $79 \pm 21$ & 0.459 \\
\hline$\stackrel{\mathscr{E}}{\mathscr{D}}$ & & & Median (IQR) & Median (IQR) & \\
\hline$\underset{E}{E}$ & Handgrip (kg) & & $6.7(1.7)$ & $6.8(2.7)$ & 0.299 \\
\hline$\cdot \frac{\tilde{v}}{\infty}$ & One-leg stance (s) & & $15(16)$ & $9(7)$ & $0.001^{*}$ \\
\hline$\widehat{E}$ & 4x10 m SRT (s) & & $17(2.1)$ & $17(4)$ & 0.452 \\
\hline & Six-MWT (m) & & $390(70)$ & $375(84)$ & 0.262 \\
\hline & & & n (\%) & n (\%) & \\
\hline & Gender & Girls & $104(53.8)$ & $3(15.8)$ & \\
\hline & & Boys & $89(46.2)$ & $16(84.2)$ & \\
\hline & DDST II & Abnormal & $2(1.0)$ & $8(42.1)$ & \\
\hline & & Suspicious & $64(33.2)$ & $9(47.4)$ & $0.000^{*}$ \\
\hline & & Normal & $127(65.8)$ & $2(10.5)$ & \\
\hline & Personal-social & Abnormal & $13(6.7)$ & $8(42.1)$ & $00000 *$ \\
\hline 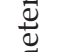 & & Normal & $180(93.3)$ & $11(57.9)$ & 0.000 \\
\hline ణ్త్ర & Fine motor & Abnormal & $16(8.3)$ & $9(47.4)$ & $0.000^{*}$ \\
\hline ?̃ & & Normal & 177 (91.7) & $10(52.6)$ & \\
\hline 苟 & Language & Abnormal & $46(23.8)$ & $9(47.4)$ & 0050 \\
\hline 㡍 & & Normal & $147(76.2)$ & $10(52.6)$ & 0.050 \\
\hline กิ & Gross motor & Abnormal & $54(28.0)$ & 14 (73.7) & $0000^{*}$ \\
\hline & & Normal & $139(72.0)$ & $5(26.3)$ & 0.000 \\
\hline
\end{tabular}

DDST: Denver developmental screening test, MND: minor neurological dysfunction, MWT: minute walk test, SD: standard deviation, SLJ: standing long jump, SRT: shuttle run test, IQR: interquartile range, ${ }^{*}, \mathrm{p}<0.01$,

than their healthy peers in terms of other physical fitness parameters (SLJ, handgrip, oneleg stance, 4x10 m SRT, Six-MWT) and DDST II sub-parameter (language). Children with MND performed worse than their peers in physical fitness and developmental parameters.

The relationship between the physical fitness and developmental parameters was also analyzed (Table III). When positive, weak, statistically significant correlation was found between DDST II and physical fitness (oneleg stance) $(\mathrm{p}<0.05)$; there was no significant relationship between other physical fitness parameters $(p>0.05)$. As the developmental parameters of preschool children get closer to normal, there was an improvement in balance.
Table III. The relationship between DDST II and physical fitness in preschool children.

\begin{tabular}{|c|c|c|c|}
\hline & \multicolumn{2}{|c|}{ DDST II } \\
\hline & & $\mathrm{r}$ & $\mathrm{p}$ \\
\hline \multirow{5}{*}{ 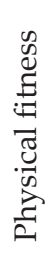 } & Handgrip $(\mathrm{kg})$ & -0.032 & 0.648 \\
\hline & One-leg stance (s) & 0.231 & $0.001^{*}$ \\
\hline & SLJ $(\mathrm{cm})$ & 0.095 & 0.170 \\
\hline & 4x10 m SRT (s) & -0.098 & 0.155 \\
\hline & Six-MWT (m) & 0.077 & 0.267 \\
\hline
\end{tabular}

*, p $<0.01$

DDST: Denver developmental screening test, MWT: minute walk test, SLJ: standing long jump, SRT: shuttle run test. 


\section{Discussion}

Developmental parameters and physical fitness of children in preschool period with a special focus on MND was evaluated in this study. Preschool children with MND had low developmental parameters and physical fitness compared to their healthy peers.

The incidence of MND in children varies according to gender, age, and prematurity. ${ }^{4,19}$ To the best of our knowledge, our study is the first to evaluate incidence of MND in preschool children without any known health problems in our country, and was determined to be $8.9 \%$ which was in line with the literature..$^{20}$

In the field of neurodevelopmental disorders, MND is studied under the umrella of Developmetal Coordination Disorder (DCD) as many children with DCD show MND. . $^{21,22}$ MND, which is thought to stem from minor aberrations of brain function undetectable on conventional neurological examination methods, is described on the problems of coordination which are uncertain movements in daily life activity, such as, impaired posture and muscle tone, insufficient gross and fine motor movements. ${ }^{23}$ Studies have also indicated that MND can be associated with learning and cognitive problems in children other than motor impairments. ${ }^{24,25}$ As for DCD, it is defined by the following four criteria: (1) acquiring and execution of coordinated motor skills is far below expected level for age, given opportunity for skill learning; (2) motor skill difficulties significantly interfere with daily life activities and impact academic/school productivity, prevocational and vocational activities, leisure and play; (3) onset is in the early developmental period; (4) motor skill difficulties are not better explained by intellectual delay, visual impairment, or other neurological conditions that affect movement. ${ }^{25}$ In other words, DCD has impairments the levels of the International Classification of Functioning, Disability and Health (ICF) such as body structure and functions (motor, sensory, cognitive, emotional), daily life activities (basic and instrumental skills), participation (at home, school and community), personal and environmental factors. ${ }^{25}$ To our knowledge, the physical fitness of preschool children with MND has not been investigated in the literature. For this reason, the physical fitness part of our study was discussed in line with DCD contaning the MND. ${ }^{21,22}$

The assessment of physical fitness in children is carried out in order to determine the physical fitness level, as well as to plan exercise programs and to follow-up progression. ${ }^{26} \mathrm{~A}$ systematic review revealed that physical fitness in children with DCD were significantly lower than their healthy peers. ${ }^{27}$ Tsiotra et al. ${ }^{28}$ in a study comparing children's physical fitness, clinically observed that, children with DCD showed lower performance than their healthy peers in terms of all physical fitness tests, but the statistical differences were shown in the handgrip strength, vertical jump and $40 \mathrm{~m}$ speed tests. Similarly, children with DCD had a statistically lower performance than their healthy peers in physical fitness tests (Six-MWT, $20 \mathrm{~m}$ running, jumping and ball throwing tests). ${ }^{29}$ Ferguson et al. ${ }^{30}$ observed that children with DCD had significantly lower handgrip strength, SLJ, $20 \mathrm{~m}$ SRT compared to their healthy peers. Focusing on MND population, as in DCD, we observed that children with MND showed statistically lower performance in terms of physical fitness (one-leg stance test) compared to their healthy peers. The relationship between the neurological status and physical fitness in our preschool children population also supported this result. In other words, physical fitness of children increases with being close to normal neurological status.

Minor Neurological Dysfunction is associated with impaired motor performance, ${ }^{31}$ difficulties in learning, spelling, literacy and arithmetic skills, ${ }^{32}$ as well as behavioral problems such as attention-deficit and social problems in schoolage children. ${ }^{31}$ In many studies involving preterm infants who were followed up until school age, it was reported that children detected with MND at school age performed lower scores in areas such as gross-motor, fine- 
motor, cognitive, daily life activities compared to their healthy peers. ${ }^{24,33}$

Similar to the studies mentioned above, we observed that preschool children with MND had lower performance scores in DDST subparameters, thus, developmental parameters are more behind compared to their healthy peers. Although language domain was also impaired, there was no statistically significant difference, which can be attributed to small sample size for this parameter.

The activities of a child affected by a developmental disorder are restricted in daily life, and the child has premature fatigue, as well as decreased exercise performance and physical fitness. ${ }^{34}$ Physical fitness levels of children with neuromotor developmental delay are lower than healthy children. The low physical fitness and long reaction times in these children are an important problem that prevents these children to perform activities independently. There are also problems in appropriate stimulus selection, adaptive response, and recording of perceived information. ${ }^{35}$ In a systematic review evaluating the studies conducted on school-age and adolescent children with neuromotor developmental delay, physical fitness parameters of children were significantly lower compared to their healthy peers. ${ }^{27}$ In another study, it was observed that children with neuromotor developmental delay showed significantly lower performance in terms of physical fitness (Six-MWT, muscle strength and endurance, speed tests, $5 \times 10 \mathrm{~m}$ agility test and balance test) compared to their healthy peers. ${ }^{34}$

There are limitations of this study such as; evaluating only children from a certain geographic location, including children only attending to kindergarten which may have an effect on developmental parameters, a limited number of children with developmental delay assessed with DDST II, and PREFIT Test Battery lacking an adaptation to Turkish children.

Beyond these limitations, to our knowledge, this is the first study to investigate the relationship between physical fitness and developmental parameters in preschool children, and positive, significant correlation was found between the DDST II and the physical fitness (one-leg stance test) in this age group. In other words, as the developmental parameters of children get closer to normal, their balance increases. Thus, the relationship between these children's developmental parameters and their physical fitness can be explained. Assessment of physical fitness or developmental parameters is important for this integrity.

In conclusion, in our study population, $8.9 \%$ of preschool children without a known health problem had MND which affects physical fitness and developmental parameters. The relationship between developmental domains and physical fitness in preschool children shows that evaluation should cover all parameters. Identifying children who have problems at an early stage will help to timely implement supportive measures in terms of physiotherapy and rehabilitation.

\section{Author contribution}

The authors confirm contribution to the paper as follows: study conception and design: AM, $\mathrm{HA}, \mathrm{GH}$; data collection: HA; analysis and interpretation of results: HA, AM, GH; draft manuscript preparation: HA, AM, GH. All authors reviewed the results and approved the final version of the manuscript.

\section{Ethical approval}

Ethical approval was obtained on 29/11/2017 from Muş Alparslan University Publication Ethics Board, with the decision number E13931, and decision number 2 .

\section{Source of funding}

No financial support/funding from any institution or organization. 


\section{Conflicts of interest}

The authors declare no conflicts of interest.

\section{REFERENCES}

1. Tanaka C, Hikihara Y, Ohkawara K, Tanaka S. Locomotive and non-locomotive activity as determined by triaxial accelerometry and physical fitness in Japanese preschool children. Pediatr Exerc Sci 2012; 24: 420-434.

2. McCollum JA. Parent education: What we mean and what that means. Top Early Child Spec 1999; 19: 147149.

3. Hadders-Algra M. The neuronal group selection theory: promising principles for understanding and treating developmental motor disorders. Dev Med Child Neurol 2000; 42: 707-715.

4. Hadders-Algra M. Two distinct forms of minor neurological dysfunction: perspectives emerging from a review of data of the Groningen Perinatal Project. Dev Med Child Neurol 2002; 44: 561-571.

5. Aylward GP. Cognitive and neuropsychological outcomes: more than IQ scores. Ment Retard Dev Disabil Res Rev 2002; 8: 234-240.

6. Yalaz K. Temel Gelişimsel Çocuk Nörolojisi (2. Basım). Ankara: Hipokrat Kitapevi, 2018.

7. Janz KF, Burns TL, Levy SM, et al. Everyday activity predicts bone geometry in children: the iowa bone development study. Med Sci Sport Exerc 2004; 36: 1124-1131.

8. Ratey JJ, Hagerman E. Spark: The Revolutionary New Science of Exercise and the Brain. (1st ed). London: Hachette Press, 2008.

9. Ortega FB, Ruiz JR, Castillo MJ, Sjostrom M. Physical fitness in childhood and adolescence: a powerful marker of health. Int J Obes (Lond) 2008; 32: 1-11.

10. Thompson PD, Arena R, Riebe D, Pescatello LS, American College of Sports Medicine ACSM's new preparticipation health screening recommendations from ACSM's guidelines for exercise testing and prescription, ninth edition. Curr Sports Med Rep 2013; 12: 215-217.

11. Hadders-Algra M. Neurological Examination of the Child with Minor Neurological Dysfunction. (3rd ed). London: Mac Keith Press, 2010.

12. Frankenburg WK, Dodds J, Archer P, Shapiro H, Bresnick B. The Denver II: a major revision and restandardization of the Denver Developmental Screening Test. Pediatrics 1992; 89: 91-97.
13. Durmazlar N, Ozturk C, Ural B, Karaagaoglu E, Anlar B. Turkish children's performance on Denver II: effect of sex and mother's education. Dev Med Child Neurol 1998; 40: 411-416.

14. Epir S, Yalaz K. Urban turkish children's performance on the Denver Developmental Screening Test. Dev Med Child Neurol 1984; 26: 632-643.

15. Cadenas-Sanchez C, Martinez-Tellez B, SanchezDelgado G, et al. Assessing physical fitness in preschool children: feasibility, reliability and practical recommendations for the PREFIT battery. J Sci Med Sport 2016; 19: 910-915.

16. Martinez-Tellez B, Sanchez-Delgado G, CadenasSanchez C, et al. Health-related physical fitness is associated with total and central body fat in preschool children aged 3 to 5 years. Pediatr Obes 2016; 11: 468-474.

17. ATS Committee on Proficiency Standards for Clinical Pulmonary Function Laboratories. ATS statement: guidelines for the six-minute walk test. Am J Respir Crit Care Med 2002; 166: 111-117.

18. de Groot JF, Takken T. The six-minute walk test in paediatric populations. J Physiother 2011; 57: 128.

19. Arnaud C, Daubisse-Marliac L, White-Koning $\mathrm{M}$, et al. Prevalence and associated factors of minor neuromotor dysfunctions at age 5 years in prematurely born children: the EPIPAGE Study. Arch Pediat Adol Med 2007; 161: 1053-1061.

20. Schendelaar P, Middelburg KJ, Bos AF, Heineman MJ, Jongbloed-Pereboom M, Hadders-Algra M. The Groningen ART cohort study: the effects of ovarian hyperstimulation and the IVF laboratory procedures on neurological condition at 2 years. Hum Reprod 2011; 26: 703-712.

21. Ferrari F, Gallo C, Pugliese M, et al. Preterm birth and developmental problems in the preschool age. Part I: minor motor problems. J Matern Fetal Neonatal Med 2012; 25: 2154-2159.

22. Vaivre-Douret L, Lalanne C, Golse B. Developmental coordination disorder, an umbrella term for motor impairments in children: nature and co-morbid disorders. Front Psychol 2016; 7: 502.

23. Kavas N, Arısoy AE, Bayhan A, et al. Neonatal sepsis and simple minor neurological dysfunction. Pediatr Int 2017; 59: 564-569.

24. Kurpershoek T, Potharst-Sirag ES, AarnoudseMoens CS, van Wassenaer-Leemhuis AG. Minor neurological dysfunction in five year old very preterm children is associated with lower processing speed. Early Hum Dev 2016; 103: 55-60. 
25. Blank R, Barnett AL, Cairney J, et al. International clinical practice recommendations on the definition, diagnosis, assessment, intervention, and psychosocial aspects of developmental coordination disorder. Dev Med Child Neurol 2019; 61: 242-285.

26. Ortega FB, Artero EG, Ruiz JR, et al; HELENA Study Group Reliability of health-related physical fitness tests in European adolescents. The Helena Study. Int J Obesity (Lond) 2008; 32(Suppl 5): S49-S57.

27. Rivilis I, Hay J, Cairney J, Klentrou P, Liu J, Faught BE. Physical activity and fitness in children with developmental coordination disorder: a systematic review. Res Dev Disabil 2011; 32: 894-910.

28. Tsiotra GD, Nevill AM, Lane AM, Koutedakis Y. Physical fitness and developmental coordination disorder in Greek children. Pediatr Exerc Sci 2009; 21: 186-195.

29. Schott N, Alof V, Hultsch D, Meermann D. Physical fitness in children with developmental coordination disorder. Res Q Exercise Sport 2007; 78: 438-450.

30. Ferguson GD, Aertssen WF, Rameckers EA, Jelsma J, Smits-Engelsman BC. Physical fitness in children with developmental coordination disorder: measurement matters. Res Dev Disabil 2014; 35: 1087-1097.
31. Peters LH, Maathuis CG, Hadders-Algra M Limited motor performance and minor neurological dysfunction at school age. Acta Paediatr 2011; 100: 271-278.

32. Kikkert HK, De Jong C, Hadders-Algra M. Minor neurological dysfunction and IQ in 9-year-old children born at term. Dev Med Child Neurol 2011; 53: e16-e25.

33. Broström L, Vollmer B, Bolk J, Eklöf E, Ådén U. Minor neurological dysfunction and associations with motor function, general cognitive abilities, and behaviour in children born extremely preterm. Dev Med Child Neurol 2018; 60: 826-832.

34. Akınoğlu B, Köse N. Hemiparetik ve diparetik serebral paralizili çocuklarda fiziksel uygunluk düzeyinin belirlenmesi. Türk Fizyoterapi ve Rehabilitasyon Dergisi 2018; 29: 11-18.

35. Ün N. Erbahceci F. The evaluation of reaction time on mentally retarded children. Pediatr Rehabil 2001; 4: $17-20$. 